\title{
Intrapair and interpair associations in verbal discrimination learning'
}

\author{
EILEEN EBERLEIN AND DAVID C. RASKIN, DEPARTMENT \\ OF PSYCHOLOGY, MICHIGAN STATE UNIVERSITY, East \\ Lansing, Mich. 48823
}

As a test of the frequency theory of verbal discrimination (VD) learning, the effect of strong associations between items within pairs was compared to the effect of strong associations between correct and incorrect items in different pairs. The interpair associations produced significant interference in VD learning, whereas intrapair associations had no effect. The results raise questions about the adequacy of the frequency theory.

According to the frequency theory of verbal discrimination (VD) learning (Ekstrand, Wallace, \& Underwood, 1966), the cue for discrimination is the subjective difference in the frequency of occurrence of the correct (C) and incorrect (I) items within a pair. Ekstrand et al proposed that frequency units may be transferred between highly associated items by means of implicit associative responses (IAR). Their results showed that a list containing associated words as the $\mathrm{C}$ items in two pairs was easier to learn than a list of unrelated words, and a list in which a word was $\mathrm{C}$ in one pair and its associate was I in another pair was more difficult to learn. A transfer experiment (Raskin, Boice, Rubel, \& Clark, in press) provided further support for the transfer of frequency units by IARs. However, the latter study found significant effects only when Ss were informed about the associative relations.

Neither of the above studies dealt with the effect of association between the items in the same pair. Ekstrand et al (1966) predicted that intrapair associations would produce interference in VD learning, as did the associations between $C$ and $I$ items in different pairs; but previous studies have produced conflicting results. Underwood \& Viterna (1951) and Youniss, Feil, \& Furth (1965) found a slight disadvantage for meaningfully similar pairs, while Putnam, Iscoe, \& Young (1962) found an advantage for such pairs. Barch, Lippman, \& Whalen (1967) found that pairs of highly associated items were easier than unrelated pairs for fourththrough eighth-grade children. The present experiment was designed to further test the frequency theory by comparing the effects of associations between $\mathrm{C}$ and I items in the same pair with associations of $\mathrm{C}$ and $\mathrm{I}$ items in different pairs. Since Raskin et al (in press) found instructions concerning the associative relationship to be of considerable importance, the effect of such instructions was also studied.

Method. Eighty-two introductory psychology students served in the experiment. They were assigned to conditions in order of appearance at the laboratory. Five groups of 16 Ss each were established on the basis of the associative relations between the items on the list and whether or not they were instructed about the relationship. In the Paired $(\mathrm{P})$ conditions the items within each pair were highly associated; the Paired-Instructed (P-I) Ss were informed of the associative relations, and the Paired-Not Instructed (P-NI) Ss were not informed. In the Unpaired (U) conditions the $\mathrm{C}$ items of each pair were highly associated with the I items of other pairs, and these conditions were also subdivided on the basis of instructions into the Unpaired-Instructed (U-I) and Unpaired-Not Instructed (U-NI) groups. The Control group received a list in which the items were not related.

The associate pairs obtained from Russell \& Jenkins (1954) and Bilodeau \& Howell (1965) were: queen-king, sweet-sour, high-low, hot-cold, hard-soft, tall-short, hammer-nail, table-chair, sky-blue, eat-food, ice-cube, green-grass. The first eight are paradigmatic associates, and the last four are syntactic associates (Deese, 1962). The additional items used in the control lists were obtained from the same sources, and there were 12 pairs in each list. The VD pairs for the $\mathrm{P}$ conditions consisted of the 12 associate pairs. The lists for the $U$ conditions contained the same items, but the two members of each associate pair appeared in different VD pairs; one member of each associate pair was the $C$ iten in its VD pair, and the other member was the $I$ item in its VD pair. The lists for the Control condition consisted of one member of an associate pair and an unrelated item. Each list was presented in two random orders with each item appearing once above and once below the other item.
The lists were presented on a Stowe memory drum. Each pair was presented for $2 \mathrm{sec}$ followed by the $\mathrm{C}$ item presented alone for $2 \mathrm{sec}$. The intertrial interval was a 2-sec blank. All Ss were given instructions which told them to learn which item was correct using the anticipation method, and they were encouraged to guess on the first trial. The P-I and U-I Ss were given the additional information that the items on the lists were associated and were given an example of associates not used on the actual list. The P-I Ss were told that the associates would appear in the same pair, and the U-I Ss were told that they would appear in different pairs. All Ss were given 10 trials.

Results. The mean total errors for the five groups are presented in Table 1. A Duncan Multiple Range test (Edwards, 1960) indicated that the $U$ groups made significantly $(p<.02)$ more errors than the $P$ and Control groups, which did not differ from each other. In order to assess the effects of Instructions, Pairing, and Type of Association on the experimental groups, each S's mean errors on each type of pair was analyzed in a 2 by 2 by 2 analysis of variance, and the means are presented in Table 2 . The $P$ groups performed significantly better than the $U$ groups, $F=$ 17.44 , df $=1 / 60, p<.001$. The main effect of Instructions and Type of Association were not significant, $F<1$. However, the interactions of Type by Instructions and Type by Pairing by Instructions were both significant, $\mathrm{F}>4.46, \mathrm{df}=1 / 60, \mathrm{p}<.05$. In the NI conditions more errors were made on paradigmatic associates than on syntactic associates. With the informative instructions, performance on the paradigmatic associates improved while performance on the syntactic associates became worse.

Discussion. The finding that strong associations between the $\mathrm{C}$ and $\mathrm{I}$ items of different pairs produced considerable interference is in accord with the frequency theory. This result is similar to that obtained by Ekstrand et al (1966), although there were slight differences in the methods of constructing the VD pairs. However, the finding that strong associations between the two items within a pair did not produce interference in learning is contrary to the prediction of the frequency theory. This finding is similar to that obtained by Edwards (1966) on within-display similarity. The frequency theory does not account for these different effects of interpair and intrapair associations. According to the theory, it makes no difference whether the associates appear in the same or different pairs; the representational response to one word is likely to be confused with the IAR made to its associate, and the frequency difference between $\mathrm{C}$ and $\mathrm{I}$ items will be reduced.

Instructions given to the Ss about the associative relations in the list did not affect the total errors or interact with the Pairing variable. The finding that the effects produced by the presence of associates in the list occurred without informative instructions is consistent with the results obtained by Ekstrand et al (1966). Apparently, instructions are necessary for producing such effects only when the associated items are presented in separate lists (Raskin et al, in press).

The results of this study seem to indicate that $S$ may use differential frequency as a cue in VD learning, but some additional process must also be operating. Relations which develop between neenbers of a VD pair may be an important part of the learning process. The model proposed by Barch et al (1967) takes this into account. According to their hypothesis, $S$ attempts to reduce the memory load by "tagging" one member of each VD pair as correct and then collapsing the pair and the tag together for memory storage. In this

Table 1

Mean Total Errors and Standard Deviations for the Five Groups and the Results of the Duncan Multiple Range Test

\begin{tabular}{|c|c|c|c|c|c|c|c|c|}
\hline \multicolumn{2}{|c|}{ P-I } & \multicolumn{2}{|c|}{ Control } & \multicolumn{2}{|c|}{ P-NI } & \multicolumn{2}{|c|}{ U-J } & U-NI \\
\hline Mean & SD & Mean & $\mathrm{SD}$ & Mean & SD & Mean & SD & Mean SI) \\
\hline 12.12 & 4.30 & 13.69 & 4.06 & 14.31 & 5.13 & 20.25 & 8.36 & $20.56 \quad 7.71$ \\
\hline
\end{tabular}

Note. Any two means underlined by the same line are not significuntl. different. 
Table 2

Mean Errors per Item Made by Experimental Groups on Paradigmatic and Syntactic Pairs

\begin{tabular}{lcc} 
Group & Syntactic & Paradigmatic \\
\hline P-I & 1.20 & .91 \\
P-NI & 1.12 & 1.27 \\
U-I & 1.77 & 1.65 \\
U-NI & 1.55 & 1.80 \\
\hline
\end{tabular}

model the combining of the members of a pair is an important part of the learning process, and the ease of combination for any pair depends on the strength of the intrapair relations as compared to alternative relations for the items. In cases where discrimination on the basis of frequency breaks down, such other factors may make a great deal of difference in VD performance.

The findings of this study concerning the interactions of type of association with instructions and pairing further demonstrate the complexity of the VD learning process. These results may be due in part to stronger associations between paradigmatic associates (.55) than between syntactic associates (.44), or they may be due to the type of associative relation. The factors which produced the differential effects of instructions and pairing on the two types of associates are not clear, and the frequency theory has not addressed itself to an explanation of such effects.

\section{REFERENCES}

BARCH, A. M., LIPPMAN, M., \& WHALEN, S. Intra-pair relations in verbal discrimination learning: A paradoxical finding. Paper read at Midwestern Psychological Association, Chicago, 1967.
BILODEAU, E. A., \& HOWELL, D. C. Free association norms by discrete and continued methods. Washington, D. C.: Office of Naval Research, 1965.

DEESE, J. Form class and the determinants of association. J. verbal Learn. verbal Behav., 1962, 1, 79-84.

EDWARDS, A. L. Experimental design in psychological research. New York: Rhinehart \& Co., 1960.

EDWARDS, D. C. Similarity in verbal discrimination. Percept. mot. Skills, $1966,23,815-820$.

EKSTRAND, B. R., WALLACE, W. P., \& UNDERWOOD, B. J. A frequency theory of verbal-discrimination learning. Psychol. Rev., 1966, 73, 566-578.

PUTMAN, V., ISCOE, I., \& YOUNG, R. K. Verbal learning in the deaf. $J$. comp. physiol. Psychol., 1962, 55, 843-846.

RASKIN, D. C., BOICE, C., RUBEL, E. W., \& CLARK, D. Transfer tests of the frequency theory of verbal discrimination learning. J. exp. Psychol., in press.

RUSSELL, W. A., \& JENKINS, J. J. The complete Minnesota norms for responses to 100 words form the Kent-Rosanoff Word Association Test. Technical Report No. 11, 1954, Contract N8-onr-66216, Office of Naval Research.

UNDERWOOD, B. J., \& VITERNA, R. O. Studies of distributed practice: IV. The effect of similarity and rate of presentation in verbal discrimination learning. J. exp. Psychol., 1951, 42, 296-299.

YOUNISS, J., FEIL, R. N., \& FURTH, H. G. Discrimination of verbal material as a function of intrapair similarity in deaf and hearing subjects. $J$. educ. Psychol., 1965, 56, 184-190.

\section{NOTE}

1. This article is based on a thesis submitted by the first author to Michigan State University in partial fulfillment of the requirements for the MA degree. 